\title{
Factors contributing to young moped rider accidents in Denmark
}

\author{
Møller, Mette; Haustein, Sonja
}

Published in:

Accident Analysis \& Prevention

Link to article, DOI:

10.1016/j.aap.2015.11.008

Publication date:

2016

Document Version

Peer reviewed version

Link back to DTU Orbit

Citation (APA):

Møller, M., \& Haustein, S. (2016). Factors contributing to young moped rider accidents in Denmark. Accident Analysis \& Prevention, 87, 1-7. https://doi.org/10.1016/j.aap.2015.11.008

\section{General rights}

Copyright and moral rights for the publications made accessible in the public portal are retained by the authors and/or other copyright owners and it is a condition of accessing publications that users recognise and abide by the legal requirements associated with these rights.

- Users may download and print one copy of any publication from the public portal for the purpose of private study or research.

- You may not further distribute the material or use it for any profit-making activity or commercial gain

- You may freely distribute the URL identifying the publication in the public portal

If you believe that this document breaches copyright please contact us providing details, and we will remove access to the work immediately and investigate your claim. 
Factors contributing to young moped rider accidents in Denmark

Mette MØLLER*, Sonja HAUSTEIN

Department of Transport, Technical University of Denmark

Bygningstorvet 116B, 2800 Kgs. Lyngby, Denmark

${ }^{*}$ corresponding author

Department of Transport, Technical University of Denmark

Bygningstorvet 115, 2800 Kgs. Lyngby, Denmark

Telephone: +45.45256537, Fax: +45.45936533, email: mm@transport.dtu.dk 
Factors contributing to young moped rider accidents in Denmark

\begin{abstract}
Young road users still constitute a high-risk group with regard to road traffic accidents. The crash rate of a moped is four times greater than that of a motorcycle, and the likelihood of being injured in a road traffic accident is 10-20 times higher among moped riders compared to car drivers. Nevertheless, research on the behaviour and accident involvement of young moped riders remains sparse.
\end{abstract}

Based on analysis of 128 accident protocols, the purpose of this study was to increase knowledge about moped accidents. The study was performed in Denmark involving riders aged 16 or 17. A distinction was made between accident factors related to (1) the road and its surroundings, (2) the vehicle, and (3) the reported behaviour and condition of the road user. Thirteen accident factors were identified with the majority concerning the reported behaviour and condition of the road user. The average number of accident factors assigned per accident was 2.7. Riding speed was assigned in $45 \%$ of the accidents which made it the most frequently assigned factor on the part of the moped rider followed by attention errors (42\%), a tuned up moped (29\%) and position on the road (14\%). For the other parties involved, attention error (52\%) was the most frequently assigned accident factor. The majority (78\%) of the accidents involved road rule breaching on the part of the moped rider.

Results indicate that preventive measures should aim to eliminate violations and increase anticipatory skills among moped riders and awareness of mopeds among other road users. Due to their young age the effect of such measures could be enhanced by infrastructural measures facilitating safe interaction between mopeds and other road users.

Keywords: Road traffic accidents, mopeds, young road users, accident analysis 


\section{Introduction}

Young road users still constitute a high-risk group with regard to road traffic accidents (e.g. World Health Organization, 2013). While much research attention has been paid to young car drivers, young moped riders have also been identified as a high-risk group (e.g. Kim et al., 1995; SWOV, 2009). The lack of research in this field was identified by Kopjar (1999). However, despite occasional studies emphasizing the severity of the problem and need for further research (e.g. Bjørnskau et al., 2012; Brandau, et al., 2011; Steg and Brussel, 2009), knowledge about the behaviour and accident risk of young moped riders remains sparse.

Knowledge on the risk behaviour of young moped riders is impeded by high levels of underreporting. Recently, an under-reporting level of 74\% was identified in Denmark (Møller et al., 2010). In addition, national accident statistics (Blackman and Haworth, 2013) and studies on road safety (Kim et al., 1995; Haworth et al., 2011; Miggins et al, 2011) often do not distinguish between different types of powered two-wheelers. Despite such impediments it has been shown that the crash rate of a moped is four times greater than that of a motorcycle (Blackman and Haworth, 2013). Further, the likelihood of being injured is 10-20 times higher among moped riders compared to drivers (Aare and Holst, 2003), and 13 times higher compared to cyclists (Brems and Munch, 2008).

Studies have identified some level of stability in risk-taking from late adolescence into early adulthood among drivers (e.g. Møller and Haustein, 2013; Vassallo et al., 2014) as well as differences in risk-taking behaviour and attitudes among pre-licensed adolescents (Mann and Lansdown, 2009; Waylen and McKenna, 2002; 2008). In many countries a moped is the first motor vehicle for many youngsters, and it is possible that riding styles and behaviour established at this stage may last long into the driving career. 
Factors such as riding speed, alcohol use, and male gender have previously been identified as key risk factors among moped and motorcycle riders (e.g. Kim et al., 1995; Miggins et al., 2011; Moskal et al., 2012). Therefore, focus on gender and possible differences regarding specific accident factors, is highly relevant. However, the mere presence of a risk factor does not necessarily lead to an accident, as an accident is the result of the interplay between several factors in a given situation. Categorizing factors into three categories, namely factors related to the road and its surroundings (1), to the vehicle (2), and to the behaviour and condition of the road user (3), has previously proven to be useful when trying to understand the mechanisms leading to road traffic accidents (e.g. Bjørnskau et al., 2012; Elliot et al., 2007; Rothengatter, 1997). This distinction will therefore also be applied in this study.

Based on national accident statistics it is possible to provide an overview of factors present at the time of the accident. However, only predefined factors included in the official registration of road traffic accidents can be included in such analyses. Thus, influence from factors such as inattention or distraction will most likely not be included, as those factors are usually not registered in the national accident statistics. In addition, the identification of new factors or provision of more detailed information about the existing factors is difficult based on accident statistics. The latter is also true for information based on standardized questionnaires, as it is difficult to ask for information about not yet identified factors. To further improve the understanding of moped accidents, studies using alternative methods to explore the interplay between factors present at the time of the occurrence of an actual accident are needed.

The present study focuses on light-moped accidents involving riders aged 16 or 17 years old. In Denmark the term light-moped refers to a powered two-wheeler with a cylinder volume of less than 50 cc. The maximum allowed speed for this type of vehicle is $30 \mathrm{~km} / \mathrm{h}$ inside as well as outside built-up areas and regardless of the speed limit of other road users. The rider must use the cycle 
path at all times, if available. Many different types of cycle paths exist, including, for example, cycle paths physically separated from the main road by a kerb, or painted road markings. Passengers are not allowed, and helmet use is mandatory. The minimum age for riding this type of moped is 16 . For persons aged 16 or 17 a moped certificate is needed. The certificate can be obtained by following a brief course which includes a combination of theory and practice.

Based on analysis of accident protocols, the purpose of the present study was to increase knowledge about moped accidents involving young riders. An exploratory approach was used in order to allow relevant but not predefined accident factors to be identified. Based on the identification of accident factors related to the road and its surroundings, the vehicle, and the reported behaviour and condition of the road users, the results can be used for the development of targeted preventive measures.

\section{Method}

\subsection{Data}

A sample of 140 accidents was drawn from the Danish national database of road traffic accidents. The sample was randomly selected based on the following criteria: The accident happened in 2007, involved a moped rider aged 16 or 17, and an equal number of accidents (14) from each police district. Twelve accidents were excluded from the analysis due to lack of available information. The total number of accidents included in the study was 128 , of which $53 \%$ involved a 16-year-old, $47 \%$ a 17 -year-old, $81 \%$ a male, and $19 \%$ a female rider. The sample constituted $20 \%$ of the total number of accidents involving a 16- or 17-year-old rider in 2007 with a very similar age and gender distribution. Permission to collect police reports was received from the Ministry of Justice. The police reports included information obtained at the accident scene, photos, testimonies provided by the road users, witnesses, and family at the time of the accident, as well as later in 
court, at the hospital or on other occasions. Baes on a template, a police report is always created when the police are sent for in relation to a road traffic accident. However, small variations in level of detail provided in each case exist. No pattern in these small variations could be identified.

\subsection{Analysis}

\subsubsection{Accident characteristics}

Based on accident protocols the following information on each accident was registered onto a common database: time, place, weather conditions, manoeuvre, parties involved, and condition of the vehicle(s). In addition, information regarding age, gender, impairment (alcohol, drugs, and illness), speed, helmet use, moped certificate, and degree of injury was registered for the moped rider as well as for the other parties involved. An overview of the accidents in terms of time of day, type of accident, counterparts and similar characteristics was provided.

\subsubsection{Accident factors and road rule breaching category}

Based on the available information each accident was reconstructed and accident factors and road rule breaching categories (see below) were assigned. Aspects of key importance for the occurrence of the accidents were identified as accident factors. All factors could be assigned to the rider as well as to the other parties involved, and multiple factors could be assigned to each accident. A distinction was made between factors related to the road and its surroundings, the vehicle, and the reported behaviour and condition of the moped rider. Accident factors concerning the road and its surroundings included weather conditions, visibility conditions (e.g. restricted access to relevant information due to the location of a road sign), objects on the road, and road design (e.g. missing/poorly maintained road markings). Accident factors concerning the vehicle included insufficient maintenance (e.g. defective brakes) and tuning up the moped (modification of 
the moped to increase its performance thereby enabling riding speeds above the legal limit). However, tuning was only assigned as an accident factor in cases where the tuning was a prerequisite for the high speed at which the accident happened). Accident factors concerning the reported behaviour and condition of all road users involved included aspects such as attention, riding speed, position on the road, impairment, and mistakes handling the vehicle. This part of the analysis was assisted by two experienced research assistants. Pilot coding was performed to ensure coding agreement.

For accident factors identified in at least 20 accidents, it was investigated whether the factors were more common among male or female riders. Group differences were examined by $\chi^{2}$ tests and are reported when significant.

Based on the reported violations each accident was assigned to a road rule breaching category (A, B, C). A was assigned if no road rule breaching was reported; B was assigned if the reported riding speed exceeded the limit, but not by more than 33\%, the rider admitted not to have paid attention to approaching traffic, and/or disobeyed the right of way; $\mathrm{C}$ was assigned if the reported riding speed was 33\% or more above the speed limit or the rider was impaired by alcohol/drugs. In addition, $\mathrm{C}$ was assigned if basic rules for riding a moped were violated by the rider (e.g. riding the moped despite not having a moped certificate, not wearing a helmet and/or riding with passengers). Gender differences in road rule breaching categories were tested ( $\chi^{2}$ test).

\section{Results}

\subsection{Accident characteristics}

An overview of the types of accidents in the sample is provided in Table 1 and compared to all registered moped accidents in the period 2004-2008 of the same age group and older adults. The sample represents the typical accident situations of young riders quite well. The majority of 
accidents of young riders happened at an intersection, and the most common type of accident involved a straight-riding moped and a right-turning motor vehicle coming from the same direction. Only 7\% of the accidents were single-vehicle accidents, while this type of accident is more common among older adults (30\%) who have by contrast fewer accidents at intersections.

In multi-vehicle crashes the majority of the other parties involved (75\%) were passenger cars. The second most frequent type was vans (10\%) followed by powered two-wheelers (6\%), cyclists (4\%), and pedestrians (3\%). The two least frequent types were buses and tractors. Most accidents (77\%) happened on weekdays (Monday 6:00 a.m. - Friday 5:59 p.m.), and 69\% in built-up areas. However, as it was not possible to control for exposure, these results essentially reflect the relative frequency with which the different vehicle types are encountered. Twelve per cent of the riders were not injured; 33\% were slightly injured; 52\% were seriously injured; and 3\% were killed.

Table 1: Type of accident for the accidents in the sample (year 2007) compared to the total registered light-moped accidents in the years 2004-2008 for the same age group and for riders aged 25-54.

\begin{tabular}{|c|c|c|c|c|c|}
\hline \multirow{2}{*}{$\begin{array}{l}\text { Type of accident } \\
\text { Age group }\end{array}$} & & \multicolumn{2}{|c|}{ Sample } & \multicolumn{2}{|c|}{ Denmark* } \\
\hline & & & 6-17 & $16-17$ & $25-54$ \\
\hline \multirow[t]{2}{*}{$N$} & & & 128 & 1370 & 1560 \\
\hline & & $N$ & $\%$ & $\%$ & $\%$ \\
\hline \multirow[t]{4}{*}{ Intersection } & Same direction, with turn & $39^{\mathrm{a}}$ & $30 \%$ & $26 \%$ & $18 \%$ \\
\hline & Crossing with turn & 18 & $14 \%$ & $14 \%$ & $9 \%$ \\
\hline & Opposite direction, with turn & 15 & $12 \%$ & $10 \%$ & $8 \%$ \\
\hline & Crossing, no turn & 12 & $9 \%$ & $13 \%$ & $8 \%$ \\
\hline \multirow[t]{5}{*}{ Non-intersection } & Opposite direction & 10 & $8 \%$ & $7 \%$ & $5 \%$ \\
\hline & Same direction & 10 & $8 \%$ & $8 \%$ & $8 \%$ \\
\hline & Objects on side of road & 9 & $7 \%$ & $9 \%$ & $11 \%$ \\
\hline & Single-vehicle & 9 & $7 \%$ & $11 \%$ & $30 \%$ \\
\hline & Objects on road & 6 & $5 \%$ & $2 \%$ & $3 \%$ \\
\hline Total & & 128 & $100 \%$ & $100 \%$ & $100 \%$ \\
\hline
\end{tabular}

${ }^{\mathrm{a}}$ In five accidents the moped was turning. In all other accidents the moped was going straight, ${ }^{*}$ Møller et al., 2010. 
A number of violations occurred in connection with the accidents. Thus, 38 (30\%) of the moped riders were not wearing a helmet, and another four wore an unfastened helmet which fell off at the time of the accident. In 21 (16\%) accidents the rider had a passenger on the moped. A total of 51 (40\%) mopeds were tuned up, enabling them to exceed the legal speed limit - in some cases enabling riding speeds as high as $100 \mathrm{~km} / \mathrm{h}$. Eight (6\%) mopeds did not have the required licence plate; six (5\%) riders did not have a moped certificate; eight (6\%) were impaired by alcohol; eleven mopeds (9\%) had defective brakes, lights or similar; and ten (8\%) were not insured as required.

\subsection{Accident factors}

Based on the analysis, 13 accident factors were identified (see Table 2). Of these, four accident factors applied to the road and its surroundings, two applied to the vehicle and seven applied to the reported behaviour and condition of the road user. Eight accident factors applied to the rider as well as to the other party involved (visibility conditions, weather conditions, road design, riding speed, attention, and position on the road, impairment, and sudden illness). Four accident factors applied to the rider only (objects on the road, tuning up, maintenance, and passengers) and one only applied to the other party involved (wrong signal). The number of accident factors identified per accident varied from 1-7 with an average of 2.7 factors per accident. 
Table 2. Overview of accident factors and number of accidents in which each factor was identified. Each accident could be assigned multiple factors.

\begin{tabular}{|c|c|c|c|c|c|}
\hline \multirow[t]{3}{*}{ Accident factor category } & \multirow[t]{3}{*}{ Accident factor } & \multicolumn{4}{|c|}{ Number of accidents } \\
\hline & & \multicolumn{2}{|c|}{ Moped rider } & \multicolumn{2}{|c|}{$\begin{array}{c}\text { Other party } \\
\text { involved }\end{array}$} \\
\hline & & $\mathrm{n}$ & $\%$ & $\mathrm{n}$ & $\%$ \\
\hline \multirow[t]{4}{*}{ The road and its surroundings } & Visibility conditions & 8 & 6.3 & 5 & 3.9 \\
\hline & Objects on (the side of) the road & 7 & 5.5 & 0 & 0.0 \\
\hline & Weather conditions & 6 & 4.7 & 4 & 3.1 \\
\hline & Road design & 3 & 2.3 & 12 & 9.4 \\
\hline \multirow[t]{2}{*}{ The vehicle } & Moped tuned up & 37 & 28.9 & 0 & 0 \\
\hline & Poorly maintained moped & 14 & 10.9 & 0 & 0 \\
\hline \multirow[t]{7}{*}{ The road user } & Riding speed & 57 & 44.5 & 5 & 3.9 \\
\hline & Attention & 54 & 42.2 & 67 & 52.3 \\
\hline & Position on the road & 18 & 14.1 & 4 & 3.1 \\
\hline & Impairment & 8 & 6.3 & 3 & 2.4 \\
\hline & Passengers & 3 & 2.3 & 0 & 0.0 \\
\hline & Illness & 1 & 0.8 & 3 & 2.4 \\
\hline & Wrong signal & 0 & 0.0 & 2 & 1.6 \\
\hline
\end{tabular}

Accident factors concerning the road and its surroundings included accidents in which the location of a tree, house or other objects outside the roadway restricted the access to relevant information. This category also included unexpected presence of an object on the roadway, weather conditions contributing to the moped rider's loss of bearings and missing/poorly maintained road markings or unusual and therefore unexpected road design contributed to the occurrence of the accident. Accident factors concerning the vehicle included accidents due to high riding speeds facilitated by the moped being tuned up, as well as accidents in which poor maintenance of the moped (brakes, lights etc.) was a key factor.

The majority of accident factors concerned the reported behaviour and condition of the road user. Riding speed was the most frequently assigned factor on the part of the rider. It was assigned in situations where the reported riding speed contributed to loss of control of the vehicle regardless of the speed limit. Attention was the most commonly assigned accident factor when including both the rider and the other party involved. It included lack of attention and attention errors. Lack of 
attention was assigned when the rider/driver overlooked the other party involved or admitted to not having paid attention to approaching traffic and/or the riding task due to engagement in other activities. Attention errors included situations in which attempts to identify and evaluate approaching traffic had failed. In some cases unexpected behaviour of the other party (such as high speed) contributed to the error. In other cases the area of attention was too narrow to identify relevant approaching traffic (e.g. paying attention to the main road only and ignoring the cycle path when preparing a left turn).

The accident factor position on the road included behaviours such as: intentional zigzag riding, riding on the wrong side of the road or cycle path, riding too close to the edge of the road and riding on the road despite availability of a cycle path. The accident factor impairment was assigned if the road user based on a test performed by the police was found impaired by alcohol or drugs, whereas passengers included situations in which the reported behaviour of a drunken passenger (e.g. swaying) caused the rider to lose control of the moped. Illness was assigned if the available information indicated that the accident was caused by a convulsive fit caused by epilepsy or other neurological or physical conditions. Wrong signal was assigned in case of indicator errors such as indicating to the right when making a left turn or no indications at all.

When looking at the combinations of the accident factors related to the moped rider's behaviour and the behaviour of the other party involved (see Table 3), we find that accidents where only the moped rider's behaviour played a role were most frequent, followed by those where both the moped rider's behaviour and the behaviour of the other party involved contributed to the accident. 
Table 3: Combinations of accident factor categories: Moped riders' behaviour by behaviour of the other party involved

\begin{tabular}{|c|c|c|c|c|c|}
\hline & & & \multicolumn{2}{|c|}{$\begin{array}{l}\text { Moped rider behaviour } \\
\text { (incl. maintenance and tuning up) }\end{array}$} & \multirow[t]{2}{*}{ Total } \\
\hline & & & No & Yes & \\
\hline \multirow{4}{*}{$\begin{array}{l}\text { Behaviour of the other } \\
\text { party involved }\end{array}$} & No & $\mathrm{N}$ & 2 & 50 & 52 \\
\hline & & $\%$ & $1.6 \%$ & $39.1 \%$ & $40.6 \%$ \\
\hline & Yes & $\mathrm{N}$ & 35 & 41 & 76 \\
\hline & & $\%$ & $27.3 \%$ & $32.0 \%$ & $59.4 \%$ \\
\hline \multirow{2}{*}{ Total } & & $\mathrm{N}$ & 37 & 91 & 128 \\
\hline & & $\%$ & $28.9 \%$ & $71.1 \%$ & $100.0 \%$ \\
\hline
\end{tabular}

In $71 \%$ of the accidents the accident factors were related to the reported behaviour and condition of the rider, in $59 \%$ to the behaviour of the other party involved, and in $29 \%$ to the road and its surroundings. The rider's behaviour contributed significantly more often to an accident compared to the behaviour of the other party involved, $\chi^{2}(1, N=128)=26.76, p<.001$.

\subsubsection{Accident factors, gender and accident type}

For accident factors that were a contributing factor in more than 20 accidents, gender differences were examined. Significant differences are presented in Table 4.

Table 4: Significant gender differences for the most frequent accident factors in relation to the moped rider

Accident factor

Gender

Female $(n=24)$

\begin{tabular}{llrrr} 
& & Female $(n=24)$ & Male $(n=104)$ & \\
\hline \multirow{2}{*}{ Moped tuned up } & $N$ & 1 & 36 & $p<.001$ \\
& $\%$ & $4.2 \%$ & $34.6 \%$ & \\
\hline \multirow{2}{*}{ Attention } & $N$ & 4 & 50 & $p=.004$ \\
& $\%$ & $16.7 \%$ & $48.1 \%$ & \\
\hline \multirow{2}{*}{ Speed } & $N$ & 3 & 54 & $p<.001$ \\
& $\%$ & $12.5 \%$ & $51.9 \%$ & \\
\hline
\end{tabular}


Tuned up mopeds contributed more to accidents of male than female riders as did attention and speeding. There was no significant gender difference for position on the road.

For the most frequent types of accidents $(n>10)$ it is reported in Table 5, how often the accidents involved an accident factor from each of the three categories (rider behaviour, behaviour of other party involved, and the road and its surroundings).

The reported behaviour and condition of the rider were most often an accident factor in “crossing, no turn” and "straight, same direction”, in both cases most often due to lack of attention. The other party involved was almost always an accident factor in "opposite direction, with turn”, again with attention as the most frequent factor. The road and its surrounding were most often an accident factor in "straight, opposite direction”, most often because of the road design.

Table 5: Most frequent types of accidents by involvement of different accident factor categories

\begin{tabular}{|c|c|c|c|}
\hline Types of accidents & Rider behaviour & $\begin{array}{r}\text { Behaviour of the } \\
\text { other party }\end{array}$ & $\begin{array}{r}\text { Road and } \\
\text { surroundings } \\
\end{array}$ \\
\hline Same direction, with turn & 23 & 31 & 3 \\
\hline$\%$ within type of accident & $59.0 \%$ & $79.5 \%$ & $7.7 \%$ \\
\hline Crossing, with turn & 13 & 11 & 6 \\
\hline$\%$ within type of accident & $72.2 \%$ & $61.1 \%$ & $33.3 \%$ \\
\hline Opposite direction, with turn & 10 & 14 & 6 \\
\hline$\%$ within type of accident & $66.7 \%$ & $93.3 \%$ & $40.0 \%$ \\
\hline Crossing, no turn & 10 & 8 & 5 \\
\hline$\%$ within type of accident & $83.3 \%$ & $66.7 \%$ & $41.7 \%$ \\
\hline \multirow{2}{*}{$\begin{array}{r}\text { Straight, same direction } \\
\% \text { within type of accident }\end{array}$} & 8 & 5 & 0 \\
\hline & $80.0 \%$ & $50.0 \%$ & $0.0 \%$ \\
\hline \multirow{2}{*}{$\begin{array}{r}\text { Straight, opposite direction } \quad n \\
\% \text { within type of accident }\end{array}$} & 6 & 6 & 5 \\
\hline & $60.0 \%$ & $60.0 \%$ & $50.0 \%$ \\
\hline \multirow[t]{2}{*}{ Other } & 21 & 1 & 12 \\
\hline & $23.1 \%$ & $1.3 \%$ & $32.4 \%$ \\
\hline \multirow[t]{2}{*}{ Total } & 91 & 76 & 37 \\
\hline & $71.1 \%$ & $59.4 \%$ & $28.9 \%$ \\
\hline
\end{tabular}




\subsection{Road rule breaching category and type of accident}

Road rule breaching categories B or C were assigned to the majority of the accidents (78\%) and more often to accidents involving a male (83.7\%) than a female rider $\left(54.1 \% ; \chi^{2}(2, N=128)=12.15\right.$, $p=.002) .70 \%$ of the accidents happened by daylight and there was no significant difference in relation to rule breaching categories, $\chi^{2}(2, N=125)=0.37, p=.83$. Table 6 provides an overview of the most common types of accidents for each road rule breaching category.

Table 6: Most common types of accidents $(n>10)$ for each road rule breaching category.

\begin{tabular}{|c|c|c|c|c|c|c|c|c|}
\hline \multirow{3}{*}{$\begin{array}{l}\text { Types of accidents } \\
\text { Within road rule breaching category }\end{array}$} & \multicolumn{8}{|c|}{ Road rule breaching category $^{\mathrm{a}}$} \\
\hline & \multicolumn{2}{|c|}{ A } & \multicolumn{2}{|c|}{ B } & \multicolumn{2}{|c|}{$\mathrm{C}$} & \multicolumn{2}{|r|}{ Total } \\
\hline & $n$ & $\%$ & $n$ & $\%$ & $n$ & $\%$ & $n$ & $\%$ \\
\hline Same direction, with turn & 14 & 50.0 & 14 & 22.2 & 11 & 29.7 & 39 & 30.5 \\
\hline Crossing, with turn & 4 & 14.3 & 11 & 1.5 & 3 & 8.1 & 18 & 14.1 \\
\hline Opposite direction, with turn & 2 & 7.1 & 8 & 12.7 & 5 & 13.5 & 15 & 11.7 \\
\hline Crossing, no turn & 2 & 7.1 & 5 & 7.9 & 5 & 13.5 & 12 & 9.4 \\
\hline Same direction & 2 & 7.1 & 5 & 7.9 & 3 & 8.1 & 10 & 7.8 \\
\hline Opposite direction & 3 & 10.7 & 5 & 7.9 & 2 & 5.4 & 10 & 7.8 \\
\hline Other & 1 & 3.6 & 15 & 23.8 & 8 & 2.6 & 24 & 18.8 \\
\hline Total & 28 & 100 & 63 & 100 & 37 & 100 & 128 & 100 \\
\hline
\end{tabular}

${ }^{\mathrm{a}} \mathrm{A}$ : no road rule breaching, B: exceeding speed limit (up to 33\%), inattention to approaching traffic, disobeying the right of way, C: exceeding speed limit (33\% or more), impairment by alcohol/drugs, violating rules for riding a moped (e.g. no certificate and/or no helmet). See also section 2.2.1.

Regardless of category, the majority of the accidents happened at an intersection, and "same direction with turn” was the most frequent type of accident. However, the relative importance of this type of accident varied between categories A, B, and C. Thus, for category A, $50 \%$ of the accidents were this type of accident, whereas it was of lower relative importance for the categories B and C. Small variations regarding the relative frequency of each accident were identified. Thus for category C accidents “crossing no turn” was of higher relative importance than for category A 
and B accidents. In addition, category B and C accidents differed from category A accidents by a larger share of the accident type "other” which is partly due to a larger share of single-vehicle accidents, and accidents in which the rider hit a parked car or other objects on the road or on the side of the road. For the majority of the different types of accidents the largest difference in relative importance of each situation was between category A and C situations.

\section{Discussion}

The main aim of this study was to increase the knowledge about moped accidents involving 1617-years-old riders. Thirteen accident factors, most of which concerned the reported behaviour and condition of the road user, were identified. The majority of the accidents involved road rule breaching on the part of the moped rider. Preventive measures should aim to eliminate violations and increase anticipatory skills among moped riders and awareness of mopeds among other road users. The effect of such measures could be enhanced by infrastructural measures such as separation of mopeds and cyclists from other road users in time and space thereby facilitating safe interaction between road users.

Most accident factors concerned the reported behaviour and condition of the road users, thereby indicating that road user behaviour is a key issue for moped safety as it is for road safety in general (Evans, 1996). Based on the number of accidents in which each accident factor was identified, attention and speed were the most pronounced, particularly among male riders. The importance of speed is supported by studies showing that speeding and/or inappropriate speed are the most influential factors for the risk of causing an accident among powered two-wheelers (Lardelli-Claret et al., 2005), and that the majority of violations among young moped riders are speeding offences (Steg and Brussel, 2009). 
In line with previous studies (e.g. Pai, 2009) accidents involving a straight-riding moped and a right-turning motor vehicle were common. The analysis provided a nuanced understanding of the interaction between the road users prior to the accidents with the speed of the moped and the attention of the other party involved as key factors. Some accidents happened despite the other party involved was aware of the approaching moped. Due to speeding the moped arrived faster than expected thereby creating safety problems, especially when at the same time opponents accept small safety margins and misjudge arrival time due to the small size of a moped (e.g. Horswill et al., 2005). Other accidents happened in situations in which the other party was not aware of the approaching moped thereby confirming previous results showing that 'looked-but-failed-too-see' situations are a key element in accidents with powered two-wheelers (e.g. Clarke, 2007). Speeding is known to be a key factor in these accidents, possibly based on the moped's location outside the scanning field of the other party involved. However, in some accidents the moped was overlooked despite not speeding. The analyses revealed that in these cases the other party was not paying appropriate attention to approaching traffic, possibly because drivers tend to focus attention towards road users constituting a threat (e.g. Herslund and Jørgensen, 2003; Summala et al., 1996), thereby increasing the likelihood of overlooking mopeds.

Compared to existing knowledge on moped accidents involving other age groups, the results show that some factors involved in moped accidents among youth differ from factors involved in moped accidents involving older riders. Firstly, among the 16-17-year-olds single-vehicle accidents account for around $10 \%$ of the accidents whereas the share among $24-54$-year-olds is three times as high (30\%). Secondly, contrary to other age groups (Kim et al., 2004; SWOV, 2009; Moskal et al., 2012; Vlahogianni et al., 2012), alcohol was not as prevalent an accident factor among youth. Although the results of this study do not allow definite conclusions on reasons for age differences in accident patterns, it is possible that they are partly due to socio-demographic differences between 
young and older moped riders. Support for this is found in a study by Miggins et al. (2011) which showed that drunk driving recidivists who had lost their license is a high-risk group among older moped riders. In addition, even though alcohol consumption among Danish youth is known to be among the highest in Europe (Hibell et al., 2011), it is lower than alcohol consumption among Danish adults. This difference is not due to age related restrictions as the legal drinking age in Denmark is 16 (18 for strong alcohol >16.8\%). Further studies looking into the influence of sociodemographic and lifestyle factors on moped accidents are thus relevant.

Based on the identified importance of the behaviour and condition of the road users, measures targeting these aspects are of key importance. Particularly police enforcement to reduce road rule breaching such as speeding, unfocussed riding and tuning the moped up are important measures. Moreover, measures to improve skills in anticipating the behaviour of other road users and appropriately adjusting own behaviour (e.g. Njå and Nesvåg, 2007) are also relevant. Improving the mandatory moped certificate course is a possible and commonly used strategy despite limited evidence of safety effects of formal training (Haworth, 2012). Lack of evidence may partly be due to methodological weaknesses (Ivers, 2011), but may also be due to inappropriately designed training programmes. Recent Dutch experiences with moped training (Goldenbeld et al, 2004) and motorcycle training (Boele and de Craen, 2014) indicate that actively engaging participants in evaluation of own behaviour and external cues is important to achieve a safety effect of training, although the long term effect is limited (Goldenbeld et al., 2004). However, even for well-designed training programmes, the effect may be limited, as recent research suggests that risk-taking behaviour increases during adolescence due to psycho-physiological development and changes in the socio-cultural environment (Boyer, 2006). Therefore, developing a forgiving road environment which protects the young road users from the consequences of their risk-taking behaviour such as speeding or unfocussed riding is also needed to improve road safety among young riders (Elvik, 
2012; Twisk et al, 2015). With regard to young moped riders a protective environment might also serve to protect the riders against being overlooked. In Denmark light-mopeds are treated as cyclists, despite a generally higher riding speed. Consequently, suggestions for a safe cycling environment such as separation in time or space (Wegman et al., 2012) may also be relevant for mopeds as suggested by the high rate of intersection accidents. However, further studies addressing differences and similarities between cyclist and moped accidents are needed to verify this.

The study was partly based on a qualitative analysis of information derived from accident protocols. Although this type of accident information has clear advantages when supplementing the more simplified and standardized information provided through accident statistics when researching accident causation mechanisms (Larsen, 2004), some limitations regarding the quality of the data need to be taken into consideration. Firstly, in line with other studies including qualitative data (e.g. Aust et al., 2012), there was some variation with regard to the details provided about the context in which the accident happened, the purpose of the trip and factors motivating the behaviour. In four cases the limited information was caused by the death of the moped rider. In other cases no explanation for the limited information was available. However, in all cases sufficient information was available to understand the accident mechanism based on the interaction between the road, the vehicle, and the road user.

The well-known high level of under-reporting of road traffic accidents is another possible limitation of the study. However, although under-reporting may bias the impression of the importance and frequency of the different accident factors identified in this study, it does not affect the result of the analysis of the reported accidents.

\section{Acknowledgements}

The authors would like to thank the three reviewers for their valuable comments and suggestions. 


\section{References}

Aare, M., Holst, H., 2003. Injuries from motorcycle and moped crashes in Sweden from 19871999. Injury Control and Safety Promotion 10, 131-138.

Aust, M.L., Fagerlind, H., Sagberg, F., 2012. Fatal intersection crashes in Norway: Patterns in contributing factors and data collection challenges. Accident Analysis and Prevention 45, 782-791.

Bjørnskau, T., Nævestad, T.O., Akhtar, J., 2012. Traffic safety among motorcyclists in Norway: A study of subgroups and risk factors. Accident Analysis and Prevention 49, 50-57.

Blackman, R.A., Haworth, N.L., 2013. Comparison of moped, scooter and motorcycle crash risk and crash severity. Accident Analysis and Prevention 57, 1-9.

Boele, M., de Craen, S. 2014. Evaluation advanced training course for motorcyclists. Motorcyclists ride safer after training. SWOV, R-2014-22E.

Boyer, T.W. 2006. The development of risk-taking: A multi-perspective review. Developmental review 26, 291-345.

Brandau, H., Daghofer, F., Hofmann, M., Spitzer, P., 2011. Personality subtypes of young moped drivers, their relationship to risk-taking behavior and involvement in road crashes in an Australian sample. Accident Analysis and Prevention 43, 1713-1719.

Brems, C., Munch, K., 2008. Risiko i Trafikken 2000-2007. Rapport 2, 2008. DTU Transport.

Clabaux, N., Brenac, T., Perrin, C., Magnin, J., Canu, B., Eslande, P.V., 2012. Motorcyclists’ speed and 'looked-but-failed-to-see’ accidents. Accident Analysis and Prevention 49, 73-77.

Clarke, D.D., Ward, P., Bartle, C., Truman, W., 2007. The role of the motorcyclist and other driver behaviour in two types of serious accident in the UK. Accident Analysis and Prevention 39, 974-981. 
Crundall, D., Crundall, E., Clarke, D., Shahar A., 2012. Why do drivers fail to give way to motorcycles at T-junctions? Accident Analysis and Prevention 44, 88-96.

Elliot, M.A., Baughan, C.J., Sexton, B.F., 2007. Errors and violations in relation to motorcyclists' crash risk. Accident Analysis and Prevention 39, 491-499.

Elvik, R. 2012. Powered two-wheelers within the traffic system. Editorial. Accident Analysis and Prevention 49, 1-4.

Evans, L., 1996. The dominant role of driver behavior in traffic safety. American Journal of Public Health 86, 784-786.

Goldenbeld, C., Twisk, D., Saskia, D.C. 2004. Short and long term effects of moped rider training: a field experiment. Transportation Research Part F. 7, 1-16.

Haworth, N. 2012. Powered two wheelers in a changing world - challenges and opportunities. Accident Analysis and Prevention 44, 12-18.

Haworth, N., Nielson, A., Greig, K., 2008. Moped crashes in Queensland. http://casr.adelaide.edu.au/rsr/RSR2007/HaworthN.pdf

Herslund, M.B., Jørgensen, N.O., 2003. Looked-but-failed-to-see-errors in traffic. Accident Analysis and Prevention 35, 885-891.

Hibell, B., Guttormsson, U., Ahlström, S., Balakireva, O., Bjarnason, T., Kokkevi, A., Kraus, L., 2012. The 2011 ESPAD Report. Substance use among students in 36 European countries. CAN.

Horswill, M.S., Helman, S., Ardiles, P., Wann, J.P., 2005. Motorcycle accident risk could be inflated by a time to arrival illusion. Optometry and Vision Science 82, 740-746.

Ivers, R. 2011. Motorcycle rider training. Cochrane corner. Injury Prevention 17, 66.

Kim, K., Takeyama, D., Nitz, L. 1995. Moped safety in Honolulu, Hawaii. Journal of Safety Research 26, 177-185. 
Kopjar, B., 1999. Moped injuries among adolescents: A significant forgotten problem? Accident Analysis and Prevention 31, 473-478.

Lardelli-Claret, P., Jiménez-Moleon, J.J., de Dios Luna-del-Castillo, J., Garcia-Martin, M., BuenoCavanillas, A., Gálvez-Vargas, R., 2005. Driver-dependent factors and the risk of causing a collision for two-wheeled motor vehicles. Injury Prevention 11, 225-231.

Larsen, L., 2004. Methods of multidisciplinary in-depth analyses of road traffic accidents. Journal of Hazardous Materials 111, 115-122.

Mann, H.N., Lansdown, T., 2009. Pre-driving adolescent attitudes: Can they change? Transportation Research Part F 12, 395-403.

Miggins, M., Lottenberg, L., Liu, H., Moldawer, L., Efron, P., Ang, D., 2011. Mopeds and scooters: crash outcomes in a high traffic state. The Journal of Trauma Injury, Infection, and Critical Care 71, 217-222.

Moskal, A., Martin, J.L., Laumon, B., 2012. Risk factors for injury accidents among moped and motorcycle riders. Accident Analysis and Prevention 49, 5-11.

Møller, M., Carstensen, G., Framke, E., 2010. Færdselsuheld blandt unge bilister og knallertkørere. DTU Rapport, 5, 2010.

Møller, M., Haustein, S., 2013. Keep on cruising: Changes in leisure time and driving style among male drivers between 18 and 23. Transportation Research Part F 20, 59-69.

Møller, M., Haustein, S., 2014. Peer influence on speeding behaviour among male drivers aged 18 and 28. Accident Analysis \& Prevention 64, 92-99.

Njå, O., Nesvåg, S.M., 2007. Traffic behaviour among adolescents using mopeds and light motorcycles. Journal of Safety Research 38, 481-492. 
Pai, C.W., 2009. Motorcyclist injury severity in angle crashes at T-junctions: Identifying significant factors and analyzing what made motorists fail to yield to motorcyclists. Safety Science 47, 1097-1106.

Rothengatter, T., 1997. Psychological aspects of road user behaviour. Applied Psychology. An International Review 46, 223-234.

Steg, L., Brussel, A., 2009. Accidents, aberrant behaviors, and speeding of young moped riders. Transportation Research Part F 12, 503-511.

Summala, H., Pasanen, E., Sievänen, J., 1996. Bicycle accidents and drivers’ visual search at left and right turns. Accident Analysis and Prevention, 28, 147-153.

SWOV, 2009. SWOV Fact sheet moped and light-moped riders. https://www.swov.nl/rapport/Factsheets/UK/FS_Moped_riders.pdf

Twisk, D., Commandeur, J.J.F., Bos, N., Shope, J., Kok, G. 2015. Quantifying the influence of safe road systems and legal licensing age on road mortality among young adolescents. Steps towards system thinking. Accident Analysis and Prevention 74, 306-313.

Vassallo, S., Smart, D., Spiteri, M., Cockfield, S., Harris, A., Harrison, W., 2014. Stability of risky driving from late adolescence to early adulthood. Accident Analysis and Prevention 72, 161168.

Vlahogianni, E.I., Yannis, G., Golias, J.C., 2012. Overview of critical risk factors in power-twowheeler safety. Accident Analysis and Prevention 49, 12-22.

Waylen, A., McKenna, F., 2002. Cradle Attitudes - Grave Consequences: The Development of Gender Differences in Risky Attitudes and Behaviour in Road Use: Summary Report, AA Foundation for Road Safety Research, UK.

Waylen, A., McKenna, F., 2008. Risky attitudes towards road use in pre-drivers. Accident Analysis and Prevention 40, 905-911. 
Wegman, F., Zhang, F., Dijkstra, A. 2012. How to make more cycling good for road safety? Accident Analysis and Prevention 44, 19-29.

World Health Organization, 2013. Global Status Report on Road Safety, 2013. WHO. 